ORIENTAL JOURNAL OF CHEMISTRY

An International Open Access, Peer Reviewed Research Journal

www.orientjchem.org
ISSN: 0970-020 X

CODEN: OJCHEG

2020, Vol. 36, No.(2):

Pg. 344-347

Brief Communication

\title{
Synthesis of Nano-silica Particles from Oryza sativa Husk
}

\author{
R. SUBITHA and G. S. PRABHA LITTIS MALAR* \\ Department of Chemistry and Research Centre, Scott Christian College (Autonomous), \\ Nagercoil-629003, Tamilnadu, India. \\ *Corresponding author E-mail: sahilamuhu@gmail.com \\ http://dx.doi.org/10.13005/ojc/360219
}

(Received: February 23, 2020; Accepted: March 24, 2020)

\begin{abstract}
Rice husk is one of the main agricultural by products of rice processing, which is brown in colour. Rice husk forms a hard protective layer around the grains of rice, and these husks are formed from the hard materials such as opaline and lignin to protect the seed during the growing period. Rice husk is an agricultural waste covering rich sources of minerals and have more than $95 \%$ silica. $\mathrm{SiO}_{2}$ is the most abundant mineral in the world. The rice husk samples procured from the suppliers were washed with water and dried for nearly $20 \mathrm{~h}$ to ensure that the rice husk is devoid of soil, dust, and rice grains particles. Rice husk was preheated at $600^{\circ} \mathrm{C}$ in muffle furnace to get ash. A simple method based on alkaline extraction followed by acid precipitation to produce pure silica. The synthesized silica nanoparticles were characterized by FT-IR, XRD and SEM-EDAX.
\end{abstract}

Keywords: Rice husk ash, Precipitation method, Muffle furnace, Silica, Nanoparticles.

\section{INTRODUCTION}

Recent technology involves waste consumption and cost decline in industrial handing out by using rice husk as a supply substance is created due to fast increase in population and industrialization'. More than half of the world's population rice is a tack food. By 2013 data around 715 million tons of rice produced per annum in the world ${ }^{2}$. Rice husk is an agricultural byproduct, which is richly obtainable in rice producing countries. Rice husk has a high ash varying from $18-20 \%$. Silica is the key component of rice husk ash varying from $85-95 \%{ }^{3}$. Rice husk $(\mathrm{RH})$ is generated during the rice production which makes it an agriculture waste. Due to its high volume it creates a management problem being the most common solutions landfilling or incineration in an open field ${ }^{4}$. Hemicelluloses, lignin, cellulose and ash are the main constituents in rice husk ${ }^{5}$. RHA chemically has a high concentration carbon (37wt\%), and presents $\mathrm{H}(8.80 \mathrm{wt} \%), \mathrm{N}$ (11.06wt\%), Si (9.01wt\%) and O (33.03wt\%). This values can vary according with location, atmospheric conditions and fertilizers used ${ }^{6-10}$. Silica is produced upon burning $\mathrm{RH}$ and subsequently cellulose and lignin are removed. $40 \mathrm{~kg}$ of ash generates in every ton of rice ${ }^{11}$. Two million tons of clean high ranking silica can be produced using rice husk as the raw

This is an Open Access article licensed under a Creative Commons license: Attribution 4.0 International (CC- BY). Published by Oriental Scientific Publishing Company @ 2018 
material to meet the high demand of various industries utilizing it ${ }^{12}$. With the ignition of rice husk obtains rice husk ash which has high silica content, 87-97\% ${ }^{13,9,14}$, $92-97 \%{ }^{15}$, with an amorphous structure. The silica in the ash undergoes structural changes depending on the temperature, at $550-800^{\circ} \mathrm{C}$ amorphous silica is formed and at greater temperatures, crystalline silica is formed. RHA modified material is incomparable interms of potency and stability concert ${ }^{16-18}$. Amorphous silica, will form when $\mathrm{RH}$ ash burning below temperature $700^{\circ} \mathrm{C}$. $\mathrm{Na}, \mathrm{Fe}, \mathrm{Ca}$, $\mathrm{K}$, etc are several metallic impurities produced by rice husk ash, that can decrease rice husk silica purity and surface area ${ }^{19}$. Eliminating these metallic impurities is required to obtain high purity silica by hydrochloric or sulfuric acid leaching of rice husk followed by controlling combustion ${ }^{20}$. $\mathrm{RH}$ is used as fuel in the production of energy ${ }^{1}$ and it's ash in the cement industry due to is pozzolanic properties, as a filler in polymers and rubbers ${ }^{21}$, ceramic industry ${ }^{22}$ ash as an adsorbent of heavy metals ${ }^{23}$. Silica is a bioactive element concerned as having fungicidal properties $^{24}$. Polymer/Silica nanocomposites exhibit markedly an improved properties when compared to their traditional composites due to their nano sizes inorganic filler ${ }^{25}$. A simple method based on alkaline extraction followed by acid precipitation to produce pure silica.

\section{EXPERIMENTAL AND METHODS}

\section{Materials}

Sodium hydroxide, hydrochloric acid, buffer solution was used. All of them were supplied by Sigma Aldrich as well.

\section{Rice husk}

Rice husk is one of the main agricultural by products of rice processing, which is brown in colour. Rice husk forms a hard protective layer around the grains of rice, and these husks are formed from the hard materials such as opaline silica and lignin to protect the seed during the growing period. The rice husk samples obtained from the local rice producers were used as silica source for the synthesis of silica nanoparticles using chemical methods. Husk of the local samba paddy variety alone was used.
Rice husk ash preparation (chemical treatment)

The rice husk samples procured from the suppliers were washed with water and dried for nearly $20 \mathrm{~h}$ to ensure that the rice husk is devoid of soil, dust, and rice grains particles. Then, the cleaned rice husks are burned for $2 \mathrm{~h}$ at $600^{\circ} \mathrm{C}$ and left to cool down for 10 hours. Finally, these ashes were crushed into finely ground powder.

\section{Synthesis of pure silica from rice husk ash}

A sample of $10 \mathrm{~g}$ rice husk ash was stirred in $2.5 \mathrm{M} \mathrm{NaOH}$ solution. The solution was heated in a covered beaker for $4 \mathrm{~h}$ by stirring constantly and allowed to settle down for a day and the solution was filtered. Dil. hydrochloric acid was added to the filtrate under constant stirring at controlled conditions until it reached $\mathrm{pH}$ and then buffer solution was added up to $\mathrm{pH} 8.5$ for ascertaining purity and allowed to stand at room temperature for 3 hour. The precipitate was washed for several times with deionised water, and dried in hot air oven at $100^{\circ} \mathrm{C}$ for $16 \mathrm{~h}$ to obtain pure silica.
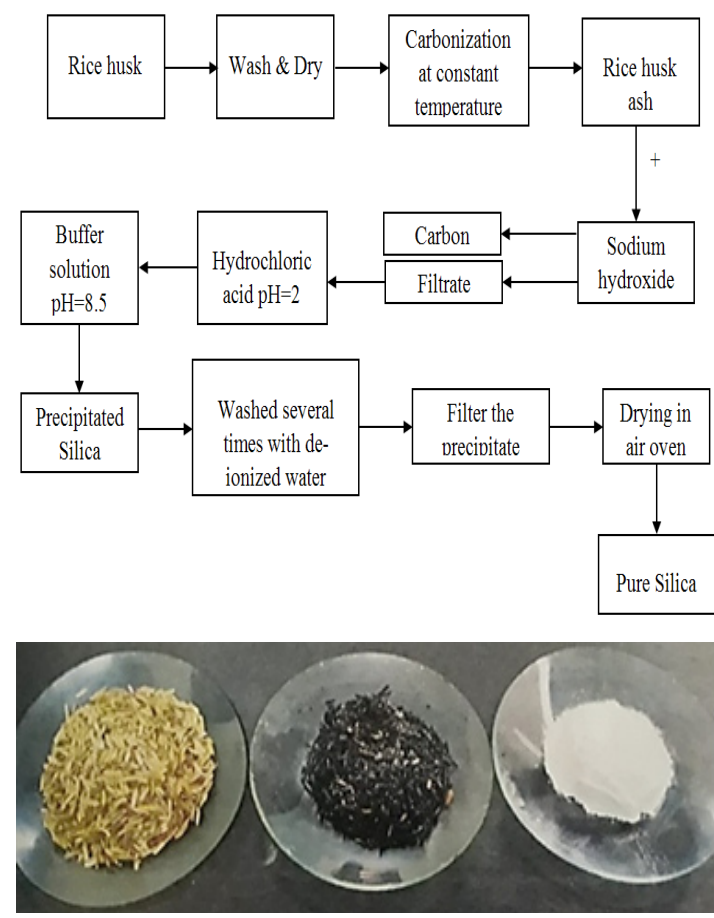

Fig.1. Photograph of silica nanoparticles formation

Testing of rice husk ash

Chemical reaction for the Silica precipitation includes. 
Ash $+2 \mathrm{NaOH} \rightarrow \mathrm{Na}_{2} \mathrm{SiO}_{3}+\mathrm{H}_{2} \mathrm{O}$

$\mathrm{Na}_{2} \mathrm{SiO}_{3}+2 \mathrm{HCl} \rightarrow \mathrm{SiO}_{2}+2 \mathrm{NaCl}+\mathrm{H}_{2} \mathrm{O}$

Flow diagram for the process of Silica Preparation:

\section{RESULT AND DISCUSSION}

Silica obtained from rice husk was subjected to the following analyses to ensure the quantity of the product obtained.

\section{FT-IR Analysis}

The FT-IR spectra of silica nanoparticles obtained in the range $400-4000 \mathrm{~cm}^{-1}$. The FT-IR data were recorded by the Shimadzu European Model.

In FT-IR spectrum the strong broad IR band is around $3447.00 \mathrm{~cm}^{-1}$ is obtained due to the stretching vibration of $\mathrm{O}-\mathrm{H}$ bonds due to silanol hydroxyl groups and absorbed water $(\mathrm{H}-\mathrm{O}-\mathrm{H})$ molecule. The IR peak at $1638.13 \mathrm{~cm}^{-1}$ is associated with bending vibration of water molecules trapped in silica matrix.

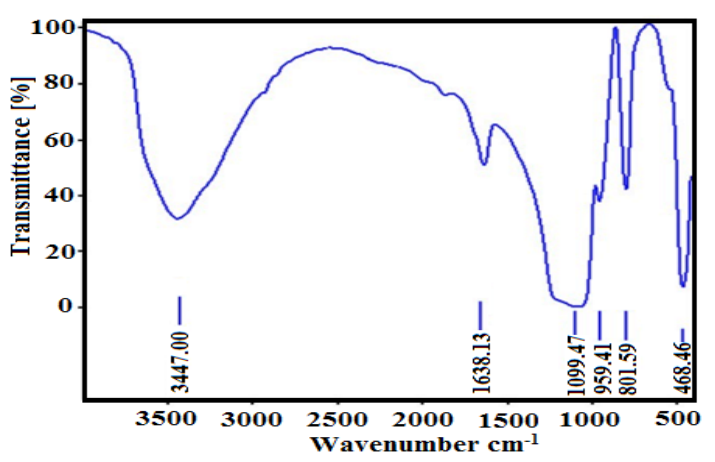

Fig. 2. FT-IR spectrum of silica nano particles

The structural siloxane band at 1099.47 $\mathrm{cm}^{-1}$ is associated with $\mathrm{Si}-\mathrm{O}-\mathrm{Si}$ asymmetric stretching vibration. The bending vibration at $959.41 \mathrm{~cm}^{-1}$ was attributed to $\mathrm{Si}-\mathrm{OH}$ silanol groups. The absorption bands at $801.59 \mathrm{~cm}^{-1}$ is due to $\mathrm{Si}-\mathrm{O}$ symmetric stretching vibration. The IR band at $468.46 \mathrm{~cm}^{-1}$ is due to Si-O-Si bending vibration.

\section{X-ray diffraction pattern}

$X$-ray diffraction is a versatile, nondestructive technique used for identifying the crystalline phases present in the solid materials and powders and for analyzing structural properties of the phases.

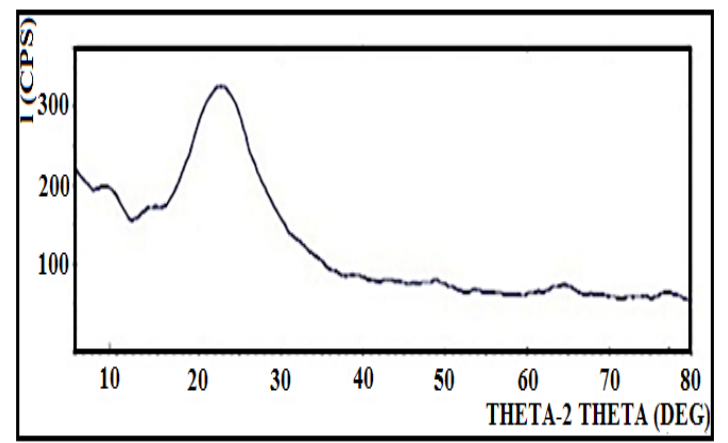

Fig. 3. XRD pattern of silica nanoparticles

Shape of silica nanoparticles was definite by XRD analysis as shown in Fig. 2. X-ray diffraction pattern for rice husk ash below $600^{\circ} \mathrm{C}$ for $2 \mathrm{~h}$ shows broad peak. The major peak was observed at $2 \theta=220$. The broad peaks deep-rooted amorphous nature of nanosilica.

\section{Scanning electron microscopy (SEM)}

SEM is a type of electron microscope that produces image of a sample by scanning the surface with a focused beam of electrons. SEM images of silica nanoparticles shown in Fig. 3. SEM images showed the absorption of spherical shaped silica nanoparticles and conclude that silica is amorphous in nature.

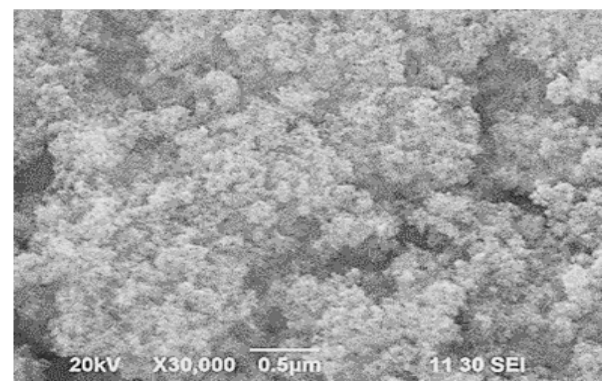

Fig. 4. SEM image of silica nanoparticles

\section{Energy dispersive X-ray spectroscopy (EDX)}

The EDX technique detects $X$-ray emitted from the sample during bombardment by an electron beam to characterize the elemental composition of the analysed volume.

Energy dispersive $\mathrm{X}$-ray definite the pattern of silica nanoparticles shown in Fig. 4. Silica and 
oxygen are the main constituent elements of the silica nanoparticles.

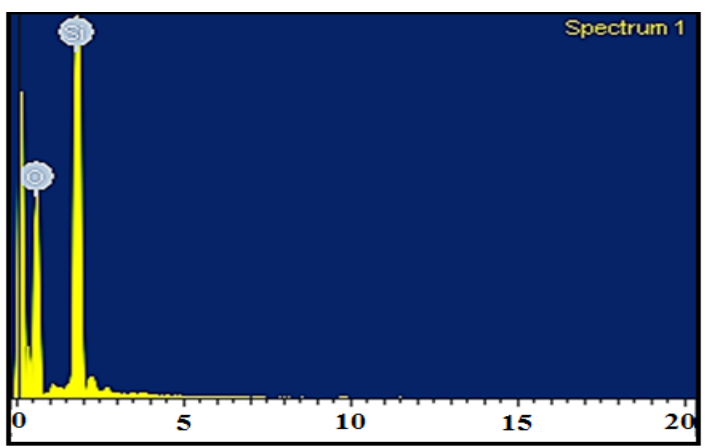

Fig. 5. EDX image of silica nanoparticles

Elemental analysis shows the atomic and weight percentage of silica nanoparticles. The weight percentage of silica is 37.99 and oxygen is 62.01 . The atomic weight percentage of silica is 25.87 and oxygen is 74.13 .

\begin{tabular}{ccc}
\hline Element & Weight percentage & Atomic percentage \\
\hline $\mathrm{Si}$ & 37.99 & 25.87 \\
$\mathrm{O}$ & 62.01 & 74.13 \\
\hline \multicolumn{3}{c}{} \\
& CONCLUSION
\end{tabular}

The present study originate that rice husk was a valuable by-product. The silica obtained from rice husk ash is amorphous in nature. Waste product of rice husk was non-hazardous, economical, low cost eco friendly and help in reducing disposal problem. By using simple precipitation method recover $95 \%$ of silica from rice hush ash.

\section{ACKNOWLEDGEMENT}

I thank STIC India, Cochin University, Kerala.

\section{Conflict of interest}

The authors declare that this is no conflict of interest financially or otherwise.

\section{REFERENCES}

1. Kumar, S.; Sangwan, P.; Mor,R.; Dhankhar, V.; Bidra, S. Res. J. Chem. Environ. Sci., 2013, 1, 126-129.

2. Muthayya, S.; Sugimoto, J.D.; Montgomery, S.; Maberly, G.F. Ann. N. Y. Acad. Sci., 2014, 1324, 7-14.

3. Mehta, A.; Ugwekar, R.P. Int. J. Eng. Res Appl., 2015, 5, 43-48.

4. Gu, S.; Zhou, J.; Yu, C.; Luo, Z.; Wang, Q.; Shi, Z. Ind. Crops Prod., 2015, 65, 1-6.

5. Carmona,V.B.; Oliveira, R.M.; Silva, W.T.L.; Mattoso, L.H.C.; Marconcini, J. M. Ind Crops Prod., 2013, 43, 291-296.

6. Chandrasekhar, S.;Pramada, P.N.; and Praveen, L. J. Mater. Sci., 2005, 40, 6535-6544.

7. Xiong, L.;Saito, K.; Sekiya, E.H.;Sujaridworakun, P.; Wada, S. J. Met. Mater. Miner., 2009, 19, 73-77.

8. Sarangi, M.; Bhattacharyya, S.; Behera, R.C. Phase Transitions., 2009, 82, 377-386.

9. Kurama, H. Int. Min. Congr. Exhib. Turkey., 2003, 18, 431-436.

10. Zerbino, R.; Giaccio, G.; Isaia, G.C. Constr. Build Mater., 2011, 25, 371-378.

11. Todkar, B.S., Deshmukh, S.M., Deorukhka, O. A. Int . J .Eng Res. Development., 2016, 12, 69-74.

12. Chandrasekhar, S.; Pramada, P.N.; Praveen, L. J. Mater. Sci., 2005, 40, 6535-6544.
13. Yalçin, N.; and Sevinç, V.; Ceram. Int., 2001, 27, 219-224.

14. Shinohara, Y.; and Kohyama, N. Ind. Health., 2004, 42, 277-285.

15. Shen, J.; Liu, X.; Zhu, S.; Zhang, H.; Tan, J. Mater. Lett., 2011, 65, 1179-1183.

16. Anwar, M.; Miyagawa, T.; Gaweesh, M. Waste Manage. Series., 2000, 1, 671-684.

17. Sousa Coutinho, J. Cement and Concrete Composites., 2003, 25, 51-59.

18. Zain, M.F.M.; Islam, M.N.; Mahmud, F.; Jami, M., Constr. Build. Mater., 2011, 25, 798-805.

19. Dominic,M.; Begum,P.; Joseph,R.; Joseph,D.; Kumar, P.; Ayswarya, Int. J. Sci. Environ and Technol., 2013, 2, 1027-1035.

20. Abu Bakar,R.; Yahya ,R.; Gana, S. Procedia Chemistry., 2016, 19, 189-195.

21. Soltani, N.; Bahrami, A.; Pech-Canul, M. I.; González, L. A. Chem. Eng. J., 2015, 264, 899-935.

22. Gonçalves M.R.F.; Bergmann, C. P. Constr. Build. Mater., 2007, 21, 2059-2065.

23. Ahmaruzzaman, M.; Gupta, V.K. Ind. Eng. Chem. Res., 2011, 50, 13589-13613.

24. Bekker, T.; Kaiser, C.; Labuschagne, N. South African Journal of Plant and Soil., 2009, 26, 55-57.

25. Tyagi, M.; and Tyagi, D. Int. J. Electro and Electrical Eng., 2014, 7, 603-608. 